\title{
Affective (re)orientations in online discussions on the threat of violence posed by migrants
}

\section{Virkki, Tuija}

2020-05-03

Virkki , T \& Venäläinen , S 2020 , ' Affective (re)orientations in online discussions on the threat of violence posed by migrants ' , Social Identities , vol. 26 , no. 3 , pp. 403-418 . https://doi.org/10.1080/13504

http://hdl.handle.net/10138/336521

https://doi.org/10.1080/13504630.2020.1767055

acceptedVersion

Downloaded from Helda, University of Helsinki institutional repository.

This is an electronic reprint of the original article.

This reprint may differ from the original in pagination and typographic detail.

Please cite the original version. 


\title{
Affective (Re)orientations in Online Discussions on the Threat of Violence Posed by Migrants
}

Tuija Virkki, University of Jyväskylä

Satu Venäläinen, University of Helsinki

\begin{abstract}
Online discussions are rife with fear-evoking images and meaning making that highlight a perceived threat to the security of European nations and their inhabitants posed by migrants' violence in the wake of increased immigration. This paper examines the role of emotions in shaping anti-immigration views as a response to the threat of violence attached to migrants in online conversations. Using a dataset of Finnish online discussion threads from 2015-2017 that were prompted by extensive media attention paid to various cases of violent crime in which migrants were suspects, we particularly analyse the affective dynamics of interpellation processes wherein discussants are invited to adopt anti-immigration orientations. This analysis demonstrates how emotions such as fear, hate, and love function together in complex ways to constitute and shift meanings constructed during these discussions. These processes afford the construction and adoption of affectively appealing identities that are based on the re-signification of anti-immigration orientations as morally and socially acceptable, such as 'normal citizen' and 'caring parent'. The analysis thus provides insight into processes in which 'ordinary' citizens hear, and respond to the call for xenophobic positions, thereby illustrating how a sense of community and caring for a community is built within these affective processes.
\end{abstract}

Keywords: affects, anti-immigration, xenophobia, interpellation, orientations, violence 


\section{Introduction}

In recent years, Finland, alongside several other European countries, has seen a remarkable increase in expression of nationalist, racist, and xenophobic views (e.g., Hübinette \& Lundström, 2014; Keskinen, 2014, 2018). These views tend to be articulated in response to increased immigration, as was the case of the so-called refugee crisis of 2015. Statistics reveal that hate crimes, hate speech, and threats based on ethnicity or religion that are specifically targeted at non-White and Muslim people, have considerably increased since 2015, when more than 34, 000 asylum seekers arrived in Finland (European Union Agency for Fundamental Rights, 2018; Rauta, 2017). Despite this influx, the overall scale of immigration in Finland is modest in comparison to the rest of Europe. In 2016, merely 6.6 percent of the Finnish population were of foreign background, which is significantly less than in many other European countries (Ministry of the Interior, 2018). 2.7 percent of population were Muslims, which is also lower than the European average of 4.9 percent (Pew Research Center, 2017).

Despite differences in the actual number of migrants between countries, the 'refugee crisis' representations as an uncontrolled influx of migrants have been increasingly mobilised via efforts to garner support for a right-wing xenophobic agenda across much of the industrialised West (Sager \& Mulinari, 2018). Most importantly, the safety of citizens (particularly women) is recurrently portrayed by those who express anti-immigration views as being seriously threatened by the arrival of assumedly violence-prone migrants (especially young men). As previous research suggests (Keskinen 2018; Nagel, 2003), notions of dangerous foreigners are historically rooted in the colonial myth that non-White men 
animalistically attack White women, which has justified the imperialist and orientalist domination of non-Western regions. In the wake of globalisation, increased immigration and incidents of 'Islamic terrorism', these long-lasting myths of dangerous and violence-prone non-White men — especially those of Muslim background—have intensified and become more prominent features of transnationally circulating discourses in the industrialised West (Grewal 2017; Horsti 2017).

In our paper, we explore the circulation of the notions of threat posed by migrants in Finnish online discussions from 2015-2017. These notions were initially fuelled by extensive media attention to a dozen alleged cases of rape and other sexual offences from 2015-2016 in which the suspects were migrant men. As a security threat associated with immigration, terrorism made headlines in 2017 following a terrorist attack in Turku, one of the largest cities in Finland. In this case, a Moroccan man whose application for asylum had been rejected stabbed two Finnish women to death and injured six women as well as two men who came to assist those attacked. In online discussions, these cases are often commented on in unison with references to crime statistics that have become central to shaping views towards migrant men and immigration in general. According to statistics from 2016, 13 percent of assault offences, 34 percent of sexual offences and 12 percent of all other offences were committed by people of foreign background (Statistics Finland, 2017). In online discussions, however, these numbers are often exaggerated to portray violence committed by migrants as an even more pervasive problem to legitimise both the calls for more restrictive immigration policies and the associated claims that migrants pose a considerable threat to national security.

In this paper we are interested in investigating the role of emotions in shaping antiimmigration views in response to the alleged threat of violence attached to migrant men. By 
particularly drawing on theory developed by Sara Ahmed (e.g., 2004), we analyse the workings of emotions in interpellation processes wherein subjects are invited to adopt antiimmigration orientations. Our analysis specifically sheds light on affective processes whereby identifications aligned with anti-immigration orientations gain legitimacy among the general population, thereby becoming affectively appealing. Furthermore, the analysis illustrates how a sense of community and the caring for said community is built within these affective processes on the basis of xenophobic orientations that draw boundaries between those who apparently belong and those cast as deserving of being excluded from 'us'.

A growing body of literature demonstrates the centrality of affects in the formation, circulation, and resistance of anti-immigration stances (e.g., Arias \& Bryla, 2018; Nikunen, 2015; Pantti, 2016). This paper contributes to that scholarship a detailed analysis of affective dynamics linked with meaning making in the context of discussions that specifically focus on the threat of violence attached to migrants. We examine the workings of these affective dynamics in the context of online discussions that display characteristic features that shape meaning making and interaction. Online fora are known to evoke polarised stance taking on relevant social issues (e.g., Paasonen, 2015; Pantti, 2016) because they provide a platform for one to anonymously express potentially contentious views with scarce risk of being held accountable for such views. For the purposes of our analysis, such fora importantly help track the dynamics involved in the construction and negotiation of meanings attached to issues of high social relevance among the general population over a given duration, such as the timely issue of immigration and violent crimes committed by migrant men.

\section{Theoretical Background}


As mentioned above, our analysis is grounded in Ahmed's theorising on emotions as constitutive of subjects, objects, and relations between them. A central concept in Ahmed's work that is most relevant for our analysis is emotions' affectiveness in both senses of the word; herein we are particularly interested in what emotions do (Ahmed, 2004). One way emotions work is by shaping various kinds of actions and orientations - that is, embodied ways of relating to the world and other people (e.g., Ahmed, 2010; see also McMahon, 2016) - whereby objects such as the stranger or the nation are shaped in particular ways. The work in which emotions engage involves 'sticking' signs to bodies that are then considered the origin of the orientations adopted towards them; in other words, when others become hateful, hateful actions are then directed against them and are perceived as occurring solely for the reason that they are hateful (Ahmed, 2004). These affective orientations constitute the subjects who act, and hence neither the objects nor the subjects are assumed to pre-exist the formation of affective relations between them; rather, they become shaped according to their mutual encounters. For instance, fear is inherent neither to the subject who fears nor to the object feared but is rather a feature of their relationship in which it effectively moves the subject away from the feared object. (Ahmed, 2004.)

Ahmed's theoretical work is based on perceiving dynamism in emotions and the relations they constitute, and is therefore well suited for analysing the effectiveness of texts that circulate in the public sphere. Ahmed (2004) refers to this dynamism as an 'affective economy' (p. 8) in which emotions, signs, and bodies constantly circulate although also 'stick to' one another. Indeed, in this circulation, emotions are not merely produced but are also attached to different bodies and gain effectiveness through repetition by moving people away from and towards others. In this circulation process, objects' 'stickiness' increases as they become saturated with affects and thereby become sites of social tension (Ahmed, 2004, pp. 
10-11, 45). Importantly, meaning making and emotions become entwined in this process in which affect strengthens the impact of certain discourses (e.g., those with anti-immigration leanings) and adds to their capacity to open up and foreclose certain ways of being, knowing, acting, and feeling (Ahmed, 2004; Hartzell, 2017). Accordingly, affect is neither treated here as separate from meanings and discourses nor distinguished from emotions, as is sometimes the case in affect studies (for further discussion, see Wetherell, 2012); rather, affect is perceived as inextricably entwined with meanings and discourses.

Our analysis complements Ahmed's views with Judith Butler's (1997) theorisation on subject formation. In particular, we draw on the Althusserian notion of interpellation, which lies at the core of Butler's conceptualisation of how discursive forces operate to constitute particular kinds of subjects. In brief, interpellation refers to 'the discursive act by which subjects are constituted' (Butler \& Bell, 1999, p. 165). In interpellation, subjects are invited to identify with normative subject positions, and by aligning with these positions they are able to become socially recognisable beings (Butler, 1997). Previous studies that combine Ahmed's and Butler's theorisation analyse affective interpellation as part of on-going practices of adopting or otherwise relating to normative conceptions of humanness that are evident in, for instance, properly gendered and heteronormative behaviours and desires (Moon, 2018) as well as orientations towards feminism and their links with ethnicity (Scharff, 2011). Most relevant to our paper are recent studies that focus on affective interpellation and normative expectations associated with race, ethnicity and nationality in forming normative Whiteness and White nationalism (e.g., Hartzell, 2017). These studies demonstrate how connecting Ahmed's and Butler's theorisation is useful for uncovering the affective interpellation processes whereby meanings stick to the normative subject positions. 
In sum, we draw on Ahmed's ideas in our analysis of how certain sticky signs are constructed in online discussions (see also Nikunen, 2016) to constitute 'us' against 'others'. We specially focus on how anti-immigration orientations are shaped and justified in online discussions. Similarly to Ahmed, Butler emphasises repetitive practices—or constant doingin her theory on subject formation through interpellation, and she perceives the world and embodied subjects as materialising and becoming socially meaningful through those practices. Butler's work thus offers a complementary perspective on processes wherein antiimmigration orientations are adopted by responding to the stickiness of subject positions made desirable through the promise they hold of social acceptability to the group constituted as 'us'. In our paper, these perspectives are consolidated in an analysis that adopts an intersectional lens on social distinctions (e.g., Brah \& Phoenix, 2004) and therefore engages with complex ways whereby productive power operates through intersecting distinctions, such as those based on gender, sexuality, race, ethnicity, religion and nationality. These intersections have been essential in previous analyses of how non-White men are being constructed as a threat to both White Western women and Western societies (e.g., Grewal, 2017; Keskinen, 2011).

\section{Data and Methods}

The data analysed in this paper originate from discussion threads centred on the topic of violence committed by migrants in Finland. The data were collected in 2017 as part of a larger project that examine discourses of violence in the contemporary Finnish context. The dataset was collected via Google web searches and site-specific text search, and the purpose of collecting data was to find threads that specifically commented on the cases of violent crime whose suspects were migrants and which gained massive media attention in Finland from 2015-2017. Accordingly, the conversations included in the dataset focus on various 
cases of sexual violence and rapes perpetrated by non-White migrant men during the socalled refugee crisis of 2015 and the terrorist knife attack perpetrated against women by an asylum-seeker in 2017. Although the discussions were triggered by comments that address these cases, they generally evolved into broader conversations about immigration, with reference recurrently made to the generic category 'migrants' rather than the specific perpetrators in the cases at hand. In light of this finding, our analyses concentrate not on the portrayals of particular cases in these discussions, but rather, on the ways whereby orientations are taken to immigration and migrants in the context of discussions triggered by those portrayals.

The data comprise 463 discussion threads containing 21,789 comments that focus on violence committed by migrants. This material originates from five online discussion fora-Finland's most popular online (general-interest) discussion forum and the for a of a national newspaper, a regional newspaper, a magazine for teenaged girls, and a family magazine — and eight blog sites' comment sections, all hosted in Finland. Conversations that take place in several types of discussion fora were included due to their potential of accessing a cross-section of views held by Finland's general population rather than handling a narrow focus upon groups known for their anti-immigration or nationalist views. Some fora, for example, belong to magazines that explicitly target women, although the anonymous nature of online communication renders impossible our knowing of who the commenters really are and how exactly they are socially positioned. Typically, however, these discussions draw on gendered and heteronormative binarities of women's positions as mothers, caregivers and passive objects of men's sexual desire, and the corresponding position of men either as sexual aggressors or protectors of women and children. 
All discussion threads were publicly accessible when the data was collected and thus the data is considered to have been created within the public realm and rendered available for research purposes. To protect the discussion participants' anonymity we have omitted information about the fora from which the data extracts presented below were obtained, and we exclusively cite the dates of the posts analysed (see, e.g.,Markham \& Buchanan 2012 for a discussion of ethics issues in the internet research context). Furthermore, the extracts have been translated from Finnish into English, which should make tracing and potentially identifying the commenters rather difficult.

We endeavoured to shed light on meaning making processes in online discussions about migrant-initiated violence that appear effective in hailing actors into subject positions made available in anti-immigration discourse by specifically focussing on the mobilisation of affects in these processes. Our analysis is grounded on our own positionings as White, nativeborn Finnish women-identified researchers who approach online discussions from a critical perspective that draws on post-structural, often labelled as Foucauldian, notions about interconnections between power, knowledge, and subjecthood. This view is based upon ontological and epistemological assumptions according to which we see intersecting power relations as constantly reproduced and potentially challenged through the entwined local and global as well as discursive and affective practices that enact social distinctions and the identities based upon on those distinctions.

To examine how affects and discourse work together in interpellation in online discussions, an affective reading of the research materials based on Ahmed's (e.g., 2004) theorisation was integrated into a discursively oriented methodology that particularly draws upon the branch of Foucauldian discourse analysis (e.g., Parker, 2012). Rather than prescribe a set of 
procedures that constitute a fixed method, Foucauldian discourse analysis is based on a broad interest in techniques - both discursive and non-discursive - through which knowledge and its objects and subjects are formed in socio-historically specific ways (Arribas-Ayllon \& Walkerdine, 2008). Given our focus on identity constitution in online discussions about violence committed by migrants, our analysis specifically concentrated on unpacking the discursive and affective accomplishment of positioning (Davies \& Harré, 1990), whereby people locate themselves and others in subject positions available in any societal context and thereby enact alignments or dis-alignments with normative conceptions of proper humanity. These ideas were put into practice by reading through the data multiple times to identify patterns in how different actors are described and assigned meaning in the discussions in relation to one another. We subsequently traced the affective dynamics involved in the construction of these meanings by focussing on how these dynamics are linked with the constitution of identities in the discussions. Below, we present a reading of these affective dynamics in identity constitution and specifically zoom in on extracts that illustrate common patterns across the data set.

\section{Circulating Sticky Signs of 'Dangerous' Others}

Mamus [short for 'migrant' in Finnish] are beasts. Berserk killers and rapists. (27 November 2015)

Internet discussions about violence committed by migrant men are rife with comments of this nature which often describe migrants with words such as 'beasts' and 'berserk killers'. These words create associations between migrants and dangerousness, hence mobilising fear and hate through animalistic, dehumanising images of migrants possessed by destructive urges. Through repetition they become stuck to the figure of a migrant man and thereby constitute 
that figure as the origin of these emotions. Following Ahmed (2004), we find such words far from insignificant; in contrast, they generate effects by creating impressions of others who endanger us. In so doing, they possess the capacity to move us away from those to whose bodies the signs that indicate danger are stuck, thereby simultaneously motivating other actions aimed at securing distance between 'us' and 'them', such as denying all immigrants access to the spaces 'we' inhabit. The extract below is from a discussion thread that deny the possibility that a Finn would have been able to commit a terrorist act similar to that which took place in Turku and thus concludes that the Muslim population constitutes an unpredictable risk factor:

Surely there are also decent people among Muslims, but, since you cannot know beforehand who does what under the pretext of religion, it would be better to play it safe and return them to their home countries. (19 August 2017)

The construction of the migrant — herein specified as the Muslim population—as a figure of fear and hate invokes 'a narrative of uncertainty and crisis' (Ahmed, 2004, p. 47) that strengthens the figure's capacity to affect us. The narrative constructed in the extract above draws upon alarmist, racialism-imbued affect widely connected with Islam in the contemporary Western imaginary (Grewal, 2017) and gains unsettling force from said affect. The notion that dangerous Muslim migrants may not be easily distinguished from harmless Muslim migrants evokes profound uncertainty regarding the possibility of keeping dangerous others at bay. In the extract, deportation is suggested to regulate this uncertainty and the anxiety-laden emotions attached to it. Hence, fear and uncertainty evoked by the constructed narrative justify the exclusion of potentially dangerous others from the nation (Ahmed, 2004). This othering is based on portraying Muslims both a security threat and a symbolic threat; as 
such, they pose a more profound existential threat to Western societies (Amer \& Howarth, 2018). Due to the difficulty associated with differentiating between the decent and the indecent and the harmless and the dangerous, excluding all bodies that bear the same signs as the suspect bodies becomes legitimate. In this process, any differences among those in the 'others' class are obliterated. Accordingly, this narrative is homogenising in essence despite the apparent differences acknowledged within the 'Muslims' category.

The fear-laden orientation to migrants - particularly Muslims — evoked in the narrative relies on images of injury that migrants may inflict upon 'us' in the event that they are allowed to enter the nation unrestrictedly. The possibility of injury is central to establish fear, and the inability to pin this fear securely and permanently to 'any knowable object' (Ahmed, 2004, p. 65 ) intensifies it. In other words, the impossibility of localising fear and hate to a particular body in a circumscribed manner allows these emotions to circulate and thereby accumulate affective value. Texts such as online comments that establish associations between objects (e.g., migrants) and these emotions are central in this circulation, which strengthens the affectiveness of certain figures and, consequently, responses oriented towards excluding those perceived as posing a threat to the security of one's nation.

\section{Naturalising Xenophobic Affective Orientations}

Constructing a xenophobic affective orientation to migrants as justified in these online discussions involves a naturalisation process, whereby fear and hate become perceived as natural human responses to the threat posed by migrants' arrival. This process involves the interpellation of subjects to emotionally appealing positions of 'normal citizens': 
It is certain that every normal person is horrified and frightened when we look at the fix Finland is in because of the swarm of refugees. Whereas earlier parents were afraid only of a matu [a word coined to refer to migrants as invaders] raping their daughter in a bush, now you have to brace yourself for your daughter or wife's throat getting cut in the middle of the day at the market. The politicians' grotesque request to not 'let fear get hold of you' shows great disrespect for the citizens. Fear is a completely normal emotion and indispensable for evolution. Why on earth should we hide the feeling of fear and pretend that everything is fine when the threat is now real? (19 August 2017)

This extract exemplifies the online response to the above-mentioned knife attack in Turku in which several women were victims, portraying the current situation in Finland as highly insecure and as requiring both a collective and individual-level response. Expressions such as 'the swarm of refugees' underline the necessity and normality of fearful responses by evoking images of dangerous invaders that oppose the politicians' 'grotesque requests' to tamper with those seemingly natural feelings. The 'normal citizens' position is constructed within the extract based on one's capacity to be moved by both the violent deeds that had occurred and the threat of future violence. Here, the fear evoked by these events is naturalised via references to its functionality in evolution, while its repression or the denial of its legitimacy signifies the betrayal of citizens and, by implication, the nation. In this process, fear as a response comes to appear well grounded and hence rational, thereby allowing for those valued qualities to be simultaneously attached to the identities constituted for those who adequately understand that they should be moved by fear. 
The naturalisation of fear as well as the anger to which it is linked herein are central in inviting the reader to adopt an orientation that allows one to be recognised as one of 'us'that is, a normal citizen. In other words, such naturalisation both urges the reader to accept and cultivate one's fear and anger directed at the threatening others and establishes these emotions as criteria for national belonging (see Ahmed, 2004). The normativity attached to emotions such as fear in these discussions is rendered even clearer in the following extract, which, similarly to the previous two, comments on the 2017 terrorist attack:

Those people who are not afraid are dangerous to Finland, because they aren't willing to do enough to protect Finnish women and children either. (25 August 2017)

As the excerpt illustrates, those who refuse to fear are excluded from 'us' by being attached to danger. Fear and protective action are, in turn, collated, and fear becomes a valuable quality that permits one to be perceived as a moral actor. Those who do not feel the way they should - that is, those who do not fear-are positioned herein as dangerous traitors (cf. Keskinen, 2011) who, somewhat similarly to migrants, do not deserve to be lumped in with 'us'. Thus danger is attached to migrants and traitors alike, both of whom are viewed as jeopardising national security and therefore become legitimate objects of anger and hate (cf. Ahmed, 2004).

In summary, fear and the xenophobic orientation to which it is attached in these online discussions serve to construct the community (and its boundaries), and being affected by this fear enables one's inclusion in said community. Fear is central to the nation's constitution in this narrative, and the making of proclamations to actual and anticipated injuries linked to 
fear is cast as a patriotic act. According to Ahmed (2004), the nation's borders can be likened to skin as they are 'easily shaped or even bruised by the proximity of others' (p.2).

Identifying with this vulnerability of one's nation by adopting a fearful orientation affirms one's membership within said nation. However, whose cries of injury and impending threat of harm are heard and whose do not depends upon the speaker's status - that is, whether the speaker is more or less societally privileged (Ahmed, 2004). Indeed, proclamations of injury and fear in online discussions can be perceived as acting to cement privilege for those who are aligned with the 'normal citizen' position.

Acting in unison with fear in such nation-building projects is hate which affords attempts to defend against injury by generating a hated object (Ahmed, 2004). In generating its object, hate gathers particular bodies into collectives and is directed at the former through their perceived belonging to the latter. Furthermore, hate is intimately bound up with love, as the latter forms the group identified with, which is distinguished from the hated groups of 'others' and gains its specific shape in this process (Ahmed, 2004). In the following section, we illustrate this joint operation in the context of the online discussions analysed.

\section{Caring Orientations}

The concern expressed over the threat of violence attached to migrants in online discussions allows for the adoption of caring orientations based on an explicit desire to protect potential victims of violence from harm by undertaking preventive action. These orientations, rooted in proclamations of love for those belonging to the category 'us', provide further justification to advocate exclusionary practices, such as stricter immigration policies (cf. Lähdesmäki \& Saresma, 2014). They become specifically compelling via the affectively loaded meanings 
they allow to become attached to such practices; for instance, the following claim about sexual violence abounds in these discussions:

Every rape committed by a refugee could be prevented if the borders were closed. So that we would take care of our own citizens, our own girls. (30 November 2015)

By equating the closing of borders with caring makes room for transforming the meanings generally attached to border closing, such that moral value becomes attached to advocates of this line of action. In other words, the affective response to the threat of violence, and alongside it the measures presented as necessitated by that threat are signified as 'doing good' (Nikunen, 2016, p. 268). The orientations shaped in comments such as those cited above closely resemble those adopted in what Mulinari and Neergaard (2014, p. 53) have called 'care racism'. The authors coined the term on the basis of their analysis of what Swedish female democratic politicians stated in an interview context and whose talk they determined illustrative of this specific form of racism. At the core of such articulations of views are dichotomous assumptions that 'normal' people who are motivated by a desire to care for others (e.g., their children) cannot be racists. As Mulinari and Neergaard (2014, p. 51) noted, a common element observable in expressions of care racism is a shift from care for all to circumscribed care 'for our own'. A very similar circumscription is visible in the discussion threads we examined; those to be cared for are recurrently described as 'our own citizens', 'our girls', or 'our daughters' and are thereby distinguished from those arriving from outside Finland's borders. This distinction between the legitimate objects of care and the 'others' who threaten their - and 'our' — security constitutes hierarchies of deservingness of care that follow the lines of national borders. 
It is noteworthy that, in the process of adopting caring orientations, the bodies to be cared for-particularly those of (young) women — are produced as particularly vulnerable and in constant danger of being hurt and invaded by the other (cf. Horsti, 2017). These bodies that face danger are thereby distinctly feminised in the process of being cast as objects of care. Similar gendering is extended to those who express worry over the safety of these women or young girls — people who by doing so adopt a position of either caring mother or protective father wherein this position taking mobilises gendered sets of associations attached to these positionings (Mulinari \& Neergaard, 2014; see also Hankivsky, 2014). Hence, in addition to enacting intersecting distinctions such as those based on race and nationality, these positionings become vehicles of performing gender. This further enhances their desirability via the normalising capacity attached to appropriately gendered identity performances.

Indeed, whilst adopting caring orientations in online discussions, several users explicitly identify themselves as mothers or fathers, although the gender-neutral categorisation 'parent' is additionally frequent. This self-categorisation allows these users to appeal to culturally familiar associations with parenting and with caring protection for those under one's care. We additionally find the 'citizen' category alongside these identifications. As can be observed in the extract below, taken from a discussion thread that debates the risk of sexual violence and terrorism associated with the 'refugee crisis', this category broadens the scope of the objects of concern and the associated care beyond immediate family, to the nation and its people:

As a parent and a citizen, I am personally really worried about the safety of each of us. (18 August 2017) 
The cultural normativity of the link between caring and being identified as a proper parentor citizen—powerfully justifies any action deemed necessary for enacting care by compellingly constructing such action as a means for fulfilling parental responsibilities towards those deemed worthy of care. These meanings are key in the process of interpellation into caring positions, and it is largely from them that the call gains its force.

Thus, while care foregrounds the prevention of harm and suffering (Hankivsky, 2014), those who are positioned as the objects of such preventive action may be sharply distinguished from groups cast outside its reach. Ahmed's views assist in grasping such dynamics of power and distinction at play in connecting exclusionary practices with caring. Ahmed (2003) firstly points out that the ability to claim one is acting out of love whilst advocating exclusionary practices is imbued with power. Secondly, she asserts that doing so allows for the legitimising misuse of power in ways that are harmful for those designated as 'others' whilst purportedly aiming at the security of those with which one aligns and thus constitutes as belonging to the category 'us'. Caring orientations adopted in online discussions can indeed be perceived as enacting social distinctions by constituting some bodies as worthy of being cared for and constituting others as unworthy of care due to the threat they have come to signify. Those 'others' are thus positioned as deserving to be external to the consideration of care as well as well as external to Finnish society.

In the discussion threads analysed, these caring orientations bind participants together and are therefore central in building a sense of community. These internet discussion fora enable users to gain support from a wide group of co-discussants regarding the views they express, and they thereby facilitate the finding of a consensus that strengthens and legitimates the 
views expressed therein (Paasonen, 2015). Several comments in the data, in which the users explicitly comment on and give support for each other's views, make this process visible:

It's a relief to hear that I am not the only one who is afraid for their daughter's sake. I haven't dared speak out loud to anyone about it - probably you would only get the stamp 'racist' or 'hysterical mother' on your forehead. My heart stops every time my child doesn't answer the phone or when it's been switched off because the battery has run out. (1 December 2015)

The extract above is part of a discussion thread that debates whether or not the feeling of fear for one's daughter's safety may be considered an indication of racism. This example illustrates how a caring orientation based on re-signifying what might otherwise be signified as racism into proclamations of love of Whiteness, Finnishness, those who are like us, etc. (cf. Hartzell, 2017) becomes a possible uniting point among the discussants. This unitedness facilitates the expressing of views with racist undertones irrespective of one's acknowledged risk of receiving the derogatory labelling of 'a racist' and attaches commonsensicality to such views, thus consolidating their associations with affects that bear positive undertones. In consequence, the positionings that are aligned with a caring orientation made available in the context of these discussions come to allow for identity performances that secure one's appearance as a moral actor even amidst one's advocacy of exclusionary practices. The positionings therefore allow one to fend off accusations of racism and attach authenticity to one's efforts, which are then signified as enacting care. The sense of consensus surrounding these orientations further facilitates the shift whereby meanings associated with antiimmigration practices move from morally condemnable to morally tenable as acts and conceptions that carry meanings associated with racism begin to signify caring. 


\section{Affective Reorientations in Conversion Narratives}

In parallel with the shifts in meanings described above, changes in orientations are depicted in what may be labelled conversion narratives (Mulinari \& Neergaard, 2014; see also Nikunen, 2016). These descriptions by several users resonate with the findings of Mulinari and Neergaard (2014, p. 49), who use 'coming out' metaphors to describe female politicians' narratives wherein a former self that embodied contradictory emotions transforms into the caring self defined above. The essence of these narratives lies in the discovery that what previously appeared to be evil is in reality a virtue. The extract below illustrates the contradictory feelings that several commenters described as being linked to a change they were undergoing in their orientation following incidents such as that in Turku:

I have never been a racist, nor do I want to become one, I have so far sort of thought that it is human and even Christian to help immigrants in need. So far, I have gladly accepted that they can come here if they are in real distress. Now, to tell you the truth, I don't really know anymore what to think of this immigration tsunami, since it appears quite uncontrollable already. (19 August 2017)

The user describes a loss of certainty regarding the legitimacy of a tolerant orientation towards immigration due to the appearance of uncontrollability attached to it. 'Immigration tsunami' is an emotionally charged metaphor that describes the feeling of the uncontrollability of immigration as a natural force accompanied by unpredictable and potentially destructive consequences (see Arcimaviciene \& Baglama, 2018). This loss of certainty can be perceived as a moment of disorientation, the effects of which Ahmed (2006) 
describes as follows: '[I]t can shatter one's sense of confidence in the ground or one's belief that the ground on which we reside can support the actions that make a life feel liveable' (p. 157). This process is then based on questioning of one's prior orientation in relation to others - questioning that motivates movement away from that stance and towards a new one. In many of the conversion narratives, this shift from a tolerant identity is driven by the threat of violence drawing closer and thereby growing more tangible, and consequently creating a pressing need for change. As a response to some users' calls that others calm down in the aftermath of the terrorist attack in Turku, the following user asserts that:

People change their tune when they start to have personal experiences [of terrorism] or related to their next of kin. My daughter's life was hanging by a thread in the terrorist attack [in Stockholm]. (19 August 2017)

Several users applied similar terms to refer to their experiences or the experiences of people close to them wherein encounters with or the immediate threat of violence posed by migrants led them to abandon their tolerance towards migrants in particular and immigration in general. In the narratives, these encounters guide the user away from the threat associated with others whose impact hits too close for comfort through a rise in affectivity of the fear attached to them. As Ahmed (2000) writes, 'to withdraw from a relation of physical proximity from bodies recognized as strange is precisely to be touched by those bodies, in such a way that the subject is moved from its place' (p. 92). The following extract from a discussion thread that deals with concern about sexual violence against girls illustrates this:

But no matter how racist it may sound, I have advised my own teenage daughters to keep FAR AWAY from all foreign-looking boys. This is where we 
have arrived, even though I am certainly not proud of transmitting my racist attitude to my children. And this racism was awakened in me [only] about a month ago? But rather healthy fear and intolerance than regretting for the rest of your life? (1 December 2015)

This extract indicates the prioritisation of identification as a responsible parent-and of the accompanying practices stemming from one's fear for the safety of one's children—over identification anchored in tolerance and anti-racist sentiments. However, the extract also illustrates ambivalence based on recognising the morally troubling elements attached to this fearful orientation: racism simultaneously signifies the otherness from which the writer seeks to maintain distance, similarly to morally dubious meanings often attached to racism in public discussions (e.g., Pantti, 2016). The responsibilities attached to parenthood become relevant here in a way that contradicts the positionings characterised above; they appear as motivation counter to a racist orientation and arise from the threat of hurting one's children by contaminating them with racism. However, the user simultaneously describes the attempts to keep the racist other at a distance as having failed and this other as having infiltrated one's mind via the skin (Ahmed, 2000). This other has become an alien that one recognises as residing within oneself. The question marks in the comment above significantly maintain a sense of disorientation in that there exists discomfort in inhabiting the fearful and, as acknowledged by the user, a racist identity as well as a discomfort that arises from uncertainty in its moral legitimacy, notwithstanding all the affective and discursive efforts to legitimise such an identity.

Hence, although the fear expressed in the extract paves the way for normalising a xenophobic orientation, the disorientation that remains evident within that fear entails the possibility- 
however slight — of an ethical reorienting towards views aligned with efforts to tackle injustice and inequality. This is because disorientation highlights moral complexity and does not permit one to settle for practices that sustain injustice (Harbin, 2014). In other words, while visible in the excerpt as a slight suggestion, such ambivalence might support one's resistance towards the calls for xenophobia and not identifying with the positions based on the seductive caring orientations made available by such calls; conversely it might afford the seeking of alternative points of identification instead.

\section{Conclusion}

Cases of violence in which migrants are suspects have occupied the centre stage in recently increased concerns over security in Finland, as is the case elsewhere in Europe (Keskinen, 2014). The fears linked to these concerns revolve around the notion that the secure nation that once was is now lost on account of the rise in immigration, which is recurrently taken to constitute a threat that escapes any societal, national, or global efforts at controlling it. The figure of a violent migrant man encapsulates this threat in the contemporary cultural imagination and is imbued with affectively loaded meanings that are recurrently mobilised in anti-immigration rhetoric. This article focuses on the entwined workings of affects and discourse in the context of discussions of migrant-initiated violence to shed light on affective dynamics involved in the construction of identities that align with anti-immigration orientations.

Our analysis specifically demonstrates how affects such as fear, hate, and love operate in the processes whereby anti-immigration orientations come to appear as legitimate and desirable. These emotions work together in complex ways to form and alter certain meanings associated with migrants, on one hand, and with those holding anti-immigration views, on the other. In 
other words, our analysis illuminates the processes of re-signification whereby xenophobic orientations become emotionally appealing and gain moral acceptability. In the analysed discussions, these processes are anchored onto the construction and adoption of affectively appealing identities, such as those of normal citizens and caring parents. These identifications may be difficult to resist due to compelling moral undertones that possess the capacity to move subjects towards these positions with great force. The analysis additionally illustrates the manner in which 'usness' is constructed in relation to these discussions' affective dynamics via processes whereby the hate and fear of demonised others consolidate a sense of community. In the data, this community is built largely upon the image of shared moral principles of protection and care for 'our' citizens — especially young girls and women — that rises to special prominence due to increased immigration and the arrival of migrants (particularly migrant men). By shedding light on processes whereby xenophobic orientations come to appear and to feel acceptable among 'ordinary' people, our analysis contributes to a comprehension of the vast impact of the contemporary politics of fear in the context of immigration debates. Indeed, in the analysed discussions, becoming an ordinary citizen-one of 'us' - is made possible specifically upon the condition that one adopts a xenophobic orientation.

Based on our analysis, then, we hereby claim that online discussions about violence committed by migrants function as sites of a particularly interpellative force that incites xenophobic orientations towards migrants. The online interaction characteristics are core components in the emergence of these affective dynamics, although their reach extends far beyond meaning making in online contexts. Online fora feed in to polarised, affectively loaded, and insensitive social interaction, which subsequently allows users to express and consolidate contentious views that reiterate, for instance, racist and xenophobic logics and 
sentiments (e.g., Nikunen, 2015). However, the plurality of views expressed therein also indicates that there never exists a total consensus. The ambivalence created by an awareness of differing views can erode the moral legitimacy of xenophobic orientations and may potentially make room for reorientations based on this de-legitimation. Such ambivalences can be considered potentially affective openings that accommodate complexity with regard to questions of migration, racism, and affect. They can pave a path towards dynamics of resistance (e.g. Sundén \& Paasonen, 2018) and for identifications afforded by such dynamics. Indeed, affective engagement with ambivalence in the context of online discussions may allow for greater reflexivity that in turn entails the possibility of resisting the calls to build 'usness' upon foundations of xenophobia. 


\section{References}

Ahmed, S. (2000). Embodying strangers. In A. Horner \& A. Keane (Eds.), Body matters: Feminism, textuality, corporeality (pp. 85-97). Manchester: Manchester University Press.

Ahmed, S. (2003). In the name of love. Borderlands, 2(3), 1-41.

Ahmed, S. (2004). The cultural politics of emotion. New York, NY: Routledge.

Ahmed, S. (2006). Queer phenomenology: Orientations, objects, others. Durham, NC: Duke University Press.

Ahmed, S. (2010). Orientations matter. In D. Coole \& S. Frost (Eds.), New materialisms: Ontology, agency, and politics (pp. 234-257). Durham, NC: Duke University Press.

Amer, A., \& Howarth, C. (2018). Constructing and contesting threat: Representations of White British Muslims across British national and Muslim newspapers. European Journal of Social Psychology, 48(5), 614-628. https://doi.org/10.1002/ejsp.2352.

Arcimaviciene, L., \& Baglama, S. (2018). Migration, metaphor and myth in media representations: The ideological dichotomy of 'them' and 'us'. SAGE Open, 8(2), 113.

Arias, R., \& Bryla, M. (2018). Orientation towards otherness in the social and literary spaces of today's Europe. Palgrave Communications, 4(18), 1-5.

Arribas-Ayllon, M., \& Walkerdine, V. (2008). Foucauldian discourse analysis. In C. Willig \& W. Stainton-Rogers (Eds.), The SAGE handbook of qualitative research in psychology (pp. 91-108). London: SAGE.

Brah, A., \& Phoenix, A. (2004). Ain’t I a woman? Revisiting intersectionality. Journal of International Women's Studies, 5(3), 75-86.

Butler, J. (1997). Excitable speech: A politics of the performative. New York, NY: Routledge. 
Butler, J., \& Bell, V. (1999). On speech, race and melancholia: An interview with Judith Butler. Theory, Culture \& Society, 16(2), 163-174.

Davies, B., \& Harré, R. (1990). Positioning: The discursive production of selves. Journal for the Theory of Social Behaviour, 20(1), 43-63.

European Union Agency for Fundamental Rights. (2018). Being black in the EU. Second European Union minorities and discrimination survey. Retrieved on 14 October 2019 from https://fra.europa.eu/sites/default/files/fra_uploads/fra-2018-being-black-in-theeu_en.pdf

Grewal, K. (2017). Racialised gang rape and the reinforcement of dominant order: Discourses of gender, race and nation. London: Routledge.

Hankivsky, O. (2014). Rethinking care ethics: On the promise of an intersectional analysis. American Political Science Review, 108(2), 252-264.

Harbin, A. (2014). The disorientations of acting against injustice. Journal of Social Philosophy, 45(2), 162-181.

Hartzell, S. (2017). Everyday (anti)-racism: Rhetorical formations of white racial consciousness in contemporary public discourse. Communication Graduate Theses \& Dissertations 75. CU Scholar - University of Colorado [at] Boulder.

Horsti, K. (2017). Digital Islamophobia: The Swedish woman as a figure of pure and dangerous whiteness. New Media \& Society, 19(9), 1440-1457.

Hübinette, T., \& Lundström, C. (2014). Three phases of hegemonic whiteness: Understanding racial temporalities in Sweden. Social Identities: Journal for the Study of Race, Nation and Culture, 20(6), 423-437. 
Keskinen, S. (2011). Borders of the Finnish nation: Media, politics and rape by 'foreign' perpetrators. In E. Eide \& K. Nikunen (Eds.), Media in motion: Cultural complexity and migration in the Nordic region (pp. 107-124). Farnham: Ashgate.

Keskinen, S. (2014). Re-constructing the peaceful nation: Negotiating meanings of whiteness, immigration and Islam after a shopping mall shooting. Social Identities, 20(6), 471485.

Keskinen, S. (2018). The 'crisis' of white hegemony, neonatalist femininities and antiracist feminism. Women's Studies International Forum, 68(May-June), 157-163.

Lähdesmäki, T., \& Saresma, T. (2014). Reframing gender equality in Finnish online discussion on immigration: Populist articulations of religious minorities and marginalized sexualities. NORA - Nordic Journal of Feminist and Gender Research, 22(4), 299-313.

Markham, A., \& Buchanan, E. (2012). Ethical decision-making and internet research: Recommendations from the AoIR Ethics Working Committee (Version 2.0). Association of Internet Researchers. Retrieved on 17 December 2018 from http://www.aoir.org/reports/ethics2.pdf

McMahon, J. (2016). Emotional orientations: Simone de Beauvoir and Sara Ahmed on subjectivity and the emotional phenomenology of gender. philoSOPHIA, 6(2), 215240.

Ministry of the Interior. (2018). International migration 2017-2018-Report for Finland. Publications 25/2018. Retrieved on 14 October 2019 from http://julkaisut.valtioneuvosto.fi/handle/10024/161174

Moon, I. (2018). 'Boying' the boy and 'girling' the girl: From affective interpellation to trans-emotionality. Sexualities, 22(1-2), 65-79. 
Mulinari, D., \& Neergaard, A. (2014). We are Sweden democrats because we care for others: Exploring racism in the Swedish extreme right. European Journal of Women's Studies, 21(1), 43-56.

Nagel, J. (2003). Race, ethnicity and sexuality: Intimate intersections, forbidden frontiers. Oxford: Oxford University Press.

Nikunen, K. (2015). Politics of irony as the emerging sensibility of the anti-immigrant debate. In R. Andreassen \& K. Vitus (Eds.), Affectivity and race: Studies from the Nordic context (pp. 21-42). Farnham: Ashgate.

Nikunen, K. (2016). Media, passion and humanitarian reality television. European Journal of Cultural Studies, 19(3), 265-282.

Paasonen, S. (2015). A midsummer's bonfire: Affective intensities of online debate. In S. Paasonen, B. Hills, \& M. Petit (Eds.), Networked affect (pp. 27-42). Cambridge, MA: MIT Press.

Pantti, M. (2016). 'Despicable, disgusting, repulsive!!!' Public emotions and moralities in online discussions about violence towards refugees. Javnost - The Public, 23(4), 363381.

Parker, I. (2012). Discourse analysis: Dimensions of critique in psychology. Qualitative Research in Psychology, 10(3), 223-239.

Pew Research Center. (2017). Europe's growing Muslim population. Retrieved on 14 October 2019 from https://www.pewforum.org/2017/11/29/europes-growing-muslimpopulation/

Rauta, J. (2017). Poliisin tietoon tullut viharikollisuus Suomessa [Hate crimes recorded by police in Finland]. Poliisiammattikorkeakoulun raportteja. Tampere: Poliisiammattikorkeakoulu. 
Sager, M., \& Mulinari, D. (2018). Safety for whom? Exploring femonationalism and care-racism in Sweden. Women's Studies International Forum, 68(May-June), 149156.

Scharff, C. (2011). Towards a pluralist methodological approach: Combining performativity theory, discursive psychology and theories of affect. Qualitative Research in Psychology, 8(2), 210-221.

Statistics Finland. (2017). Statistics on offences and coercive measures. Review on offences recorded by the police, customs and border guard. Official Statistics of Finland. Helsinki: Statistics Finland.

Sundén, J., \& Paasonen, S. (2018). Shameless hags and tolerance whores: Feminist resistance and the affective circuits of online hate. Feminist Media Studies, 18(4), 643-656.

Wetherell, M. (2012). Affect and emotion: A new social scientific understanding. London: SAGE. 